\title{
La metáfora selvática. Una aproximación a los códigos simbólicos de The Asphalt Jungle de William R. Burnett
}

\author{
Carlos Mármol \\ Universidad de Sevilla \\ carlosluismarmol@gmail.com \\ https://dx.doi.org/10.12795/futhark.2013.i08.09
}

\begin{abstract}
This work analyzes the process of metaphorical construction in the novel The Asphalt Jungle, by W.R. Burnett, and his later cinematographic version directed by John Huston, who uses elements of the own literary story to change the terms of the original story to provide it with a new meaning. This process of metaphorical adaptation shows the extraordinary symbolic capacity of the literature and the film noir.

Key words: Hard-boiled. William R. Burnett, metaphorical construction, John Huston, United States, Film noir.

Resumen: Este trabajo analiza el proceso de construcción metafórica de la novela La Jungla de Asfalto, de W.R. Burnett, y su posterior adaptación cinematográfica por parte de John Huston, en la que este director de cine utiliza elementos de la propia narración literaria para subvertir los términos de la historia y dotarla de un nuevo sentido. Este proceso de traslación metafórica muestra la extraordinaria la capacidad simbólica de la literatura y el cine negro.
\end{abstract}

Palabras clave: Novela policíaca, William R. Burnett, metáfora cultural, John Huston, Estados Unidos, cine negro.

\section{Introito \\ “¿En qué se diferencia el héroe del villano?”1. \\ Jerry Palmer}

La realidad, a veces, se nos muestra a través de un sutil juego de arquetipos. La obra literaria del escritor estadounidense William R. Burnett (Springfield. Ohio. 1899-Santa Mónica. California. 1982) es buena muestra de esta afirmación. Los protagonistas de sus narraciones, los delin-

Jerry Palmer. Thrillers. La novela de Misterio. Fondo de Cultura Económica. 1983. [p.94]. 
cuentes, encarnan una de las facetas más oscuras de la sociedad. Son la metáfora de un malestar profundo. Sin embargo, también resultan extraordinariamente reales. Burnett construyó la mayoría de sus personajes a partir de la experiencia: vivió en Chicago durante los años míticos de la ley seca, cuando conoció de primera mano el tráfico ilegal de alcohol y otras sustancias y fue testigo de la irrupción de las bandas de gangsters en la vida cotidiana de los Estados Unidos, por aquel entonces un país herido por las cruentas consecuencias económicas de la Gran Depresión ${ }^{2}$. Este mundo le perseguiría ya toda la vida. Puede que incluso a su pesar. Lo siguió incluso hasta Hollywood, donde Burnett se trasladó para trabajar como guionista cinematográfico para las productoras. Ya no le abandonaría nunca: las historias de gangsters centraron su producción novelística, paralela a la escritura de películas, y lo convirtieron en uno de los grandes referentes de lo que podríamos considerar la novela negra. Esta denominación, como es sabido, procede del nombre comercial que una editorial francesa ${ }^{3}$ dio a una colección de narraciones de suspense escritas entre finales de los 20 y principios de los años 30 por escritores norteamericanos. En ellas se mostraba una realidad bronca -la de los peores años de la historia de Estados Unidos, un periodo que podría situarse entre las dos grandes guerras mundiales- marcada por la violencia, el dinero, el sexo y el crimen. El cine ya había transitado por estos mismos caminos con películas que mostraban con un lenguaje de índole expresionista los males que atormentaban al hombre en esta etapa de la historia en la que las relaciones humanas se entendían únicamente en términos de interés primario y beneficio inmediato, como si la vida no fuera más que una mera transacción económica.

La situación social de la Norteamérica en aquellos momentos terminó cristalizando en una forma literaria, la novela hard-boiled ${ }^{4}$, que nació para ser vendida en los quioscos. Estaba destinada a un público popular, pero con el correr del tiempo ha pasado a ser objeto de estudio académico y motivo de monografías críticas. No debería extrañar: en este género narrativo, y en su posterior adaptación al mundo del cine, no late simplemente el afán por contar historias. Se retrata también un tiempo y un mundo que, aunque responde a pautas concretas, está sustentado en símbolos, metáforas y personajes que trascienden lo meramente

2 El término se refiere a las consecuencias del crack bursátil que vivió Wall Street en el año 1929.

3 Se trata de la famosa Série Noire de la editorial Gallimard, publicada a partir de 1954.

4 El término hard-boiled se construye por analogía para resaltar la dureza predominante en estas narraciones. En inglés se aplica, por ejemplo, al hard-boiled egg (un huevo duro o muy cocido). En su origen la literatura identificada con este término no comprendía únicamente relatos policiacos, sino que incluía otras obras, publicadas en formato popular, donde la extrema violencia era consustancial. 
circunstancial para convertirse en arquetipos universales. Esto es: a través de sus personajes se representan una serie de valores sociales. La denominación hard-boiled está íntimamente relacionada con el tratamiento que en dichas narraciones se hace del mundo que se intenta retratar. Un universo rudo, marcado por héroes solitarios (anti-héroes, en realidad) que se enfrentan a un destino imposible de modificar, pero que debe ser asumido con todas sus consecuencias. En las novelas policiacas de esta época además de un delito (crimen, robo o similar) lo que se muestra es una determinada actitud ante el destino. En este sentido podríamos decir que construyen su propia épica a partir de una serie de códigos que han quedado instituidos hasta configurar un género (o subgénero) literario y cinematográfico propio.

Las novelas norteamericanas de detectives, publicadas en revistas Pulp ${ }^{5}$, suponen una profunda renovación de la variante narrativa centrada en el misterio y la intriga que a partir de ciertos relatos de Edgar Allan $\mathrm{Poe}^{6}$ se desarrolla en el ámbito anglosajón. Curiosamente, el género nace en América: son los relatos del autor de The Raven, ese magnífico poema sobre el horror, los que abren esta nueva vía literaria que después será explotada por autores británicos como Agatha Christie ${ }^{7}$ o G.K. Chesterton $^{8}$, entre otros, que incluso llegan a configurar una escuela institucional donde el crimen se convierte en un arte literario tan refinado como las matemáticas. Un ejercicio intelectual casi puro. Las novelas de misterio inglesas expanden el modelo que Poe esbozó al crear a Aguste Dupin $^{9}$, un personaje que aparece por primera vez en 1841 en Los crímenes de la calle Morgue. El escritor lo utilizará posteriormente en otras dos narraciones más - La carta robada y El Misterio de Marie Roget-, si bien sus motivaciones son diferentes en cada una de sus apariciones. Se trata del antecedente literario de la figura del detective: un hombre,

5 La etiqueta Pulp se aplica por extensión a las obras literarias publicadas en Estados Unidos en formato de quiosco, barato, y encuadernadas en formato rústico. El nombre se debe a que su fabricación se hacía con el desecho de la pulpa de madera. El papel que se obtenía era muy barato, generalmente amarillento, y sin guillotinar. Se utilizaba para editar historietas y novelas baratas.

$6 \quad$ El escritor norteamericano Edgard Allan Poe está considerado el padre de los relatos de detectives, así como autor de famosos cuentos de terror y misterio. También era un consumado poeta romántico.

7 Se trata de la principal autora de novelas de detectives de la escuela británica, si bien escribió también obras sentimentales. Sus dos grandes protagonistas son Hércules Poirot y Miss Marple.

8 G. K. Chesterton es un escritor inglés, célebre por su literatura basada en el ingenio y las paradojas, que creó el personaje del Padre Brown, un sacerdote católico que asume las funciones de detective.

9 El personaje de Auguste Dupin es el arquetipo literario a partir del cual se desarrolla la figura del detective que resuelve sus casos a partir de la deducción y la lógica. La línea de la escuela británica. 
en general diletante, que aplicando la lógica, el sentido de la deducción y la razón desentraña el misterio de un crimen o un asesinato. De similar estirpe -deductiva- son Sherlock Holmes y Hércules Poirot, criaturas de ficción de A. Conan Doyle ${ }^{10}$ y Christie. Esta línea de la novela policiaca, que es la considerada canónica, trabaja la intriga como el móvil narrativo principal. Concibe la trama como si fuera un acertijo, dosifica la información para crear suspense en torno a la acción, aplica fórmulas de incertidumbre psicológica y, en general, viene a ser la expresión de un mundo intelectual cerrado. Los delitos que esclarecen sus protagonistas parecen algo así como juegos y trampas de ingenio en los que, más que la violencia o la irrupción de sentimientos como la venganza, lo que predomina es la inteligencia fría, gélida. No es extraño que en muchos de estos relatos el elemento generador de misterio sea la falta de una causalidad evidente entre el asesino y el crimen. A menor motivación, más misterio. Los crímenes, aunque pudieran tener una razón y obedecer a una lógica, son presentados como hechos gratuitos, sin causa obvia. El asesino no está forzosamente obligado a matar. Elige hacerlo por una serie de circunstancias.

En el caso de la novela norteamericana de detectives estos valores se diluyen. Desaparecen. El mundo del hard-boiled es distinto. Se trata de un territorio mucho más terrestre. El crimen o el delito siguen presentes en las tramas literarias pero ya no aparecen como resultado de una extraña y perversa maldad mefistofélica, sino como la consecuencia de un ambiente social y económico concreto, definido. Dashiell Hammet ${ }^{11}$ y Raymond Chandler ${ }^{12}$, los dos autores más importantes de esta variante de la novela de detectives, son mucho más que criminalistas o urdidores de misterios. Se les podía considerar como escritores sociales, si entendemos que este término implica la pretensión de retratar un tiempo y un espacio desde el punto de vista literario. En realidad, no hablan de crímenes, aunque lo parezca, sino que explican las patologías de una sociedad donde el delito se había convertido en algo habitual. Prueba de ello es que tenían un mercado de lectores propio, como demostraron entre otras publicaciones Black Mask ${ }^{13}$, la revista Pulp más célebre de

10 El escocés Arthur Conan Doyle es el padre del famoso detective Sherlock Holmes.

11 Dashiell Hammet está considerado el padre de la novela de detectives norteamericana. Su personaje más famoso es el detective Sam Spade, que aparece en la novela El Halcón Maltés.

12 Raymond Chandler llevó el género negro a sus más altas cotas de expresión artística. Sus novelas destacan por su sentido de la ironía y el desengaño. Su principal personaje es Philip Marlowe.

13 Black Mask es la más famosa de las revistas del género Pulp. Fundada en 1920 por H.L Mencken 
todas. En ella publicaron sus relatos las principales firmas de la novela policiaca norteamericana.

\section{Una sociedad en descomposición}

El universo que reflejan es el de la Gran Depresión. El ambiente es realista y urbano. La violencia y el crimen se convierten en elementos de la vida convencional y afectan a todos por igual. No se trata de un mundo de ficción, sino de una evidencia estadística. Entre 1929 y 1933 el producto interior bruto cayó en los Estados Unidos casi un 30\%. La inversión privada se desplomó un $90 \%$. La producción industrial -el gran motor económico- descendió casi un tercio, los productos agrarios se depreciaron un $60 \%$ y la renta media de una familia bajó hasta un $40 \%$. En términos laborales la vida era una tragedia: de tener un 3\% de desempleo el año del gran crack de Wall Street se pasó a una desocupación del $25 \%$ en apenas cuatro años. El mundo norteamericano se tornó apocalíptico si se compara con la década inmediatamente anterior, los dorados años 20, cuando la opulencia y el inicio del consumismo marcaban la vida del país, como se refleja en algunas novelas de Scott Fitzgerald $^{14}$.

Es en este entorno donde surgen las novelas hard-boiled. Narraciones donde la perspectiva ya no es aristocrática ni burguesa, como ocurre en El Gran Gatsby, sino terrenal. Oscura y atosigante. En muchas de estas novelas ya no existe, como ocurría en el caso de la escuela británica, ningún enigma. No hace falta. Lo que mueve la maquinaria narrativa es el suspense. $Y$ lo que singulariza al subgénero, y probablemente sea también el factor que lo ha hecho trascender dentro del canon literario negro, es el excelente retrato ambiental de un espacio marcado por la conflictividad social. Estas novelas crean su propia mitología, en cuya cúspide está la figura del detective, aunque se trate de una reformulación del paradigma del investigador británico. Este nuevo héroe, en cierto sentido, viene a sustituir dentro la galería de símbolos norteamericanos a la figura del cowboy de los westerns.

Ya no estamos ante un hombre que aplique la deducción y la lógica como herramientas. Contemplamos a un héroe que actúa, a un hombre de acción. El registro elegido recuerda al del antihéroe moderno: un detective que trabaja solo, mal pagado, con la vida destrozada, que desconfía por norma de casi todo el mundo, asocial, que tiene vicios inconfesables y representa el arquetipo del hombre duro. No es indestructible, sino un ser que usa una coraza para protegerse del mundo

14 Scott Fitzgerald es uno de los escritores representativos de la era del jazz en Estados Unidos. 
exterior. La riqueza de matices de este personaje arquetípico, sobre el que se podría escribir mucho, permite distinguir con nitidez las diferentes etapas por las que pasa el género del hard-boiled: una primera época, la primitiva, donde Hammett es el referente esencial; seguida de una etapa posterior, la madura, que tiene en Chandler al escritor total. Otros autores repiten, con variantes, este mismo patrón narrativo que sitúa al detective y a la ambientación en el centro del relato. En algunos casos se llega incluso al punto de que la solución del crimen se da al inicio del texto para sostener el resto de la intriga no en el delito, sino en la descripción de cómo trabaja el detective. El protagonismo del nuevo héroe de estos relatos recuerda a la épica en el sentido de presentar a un guerrero zarandeado por el capricho de los dioses que, sin embargo, es capaz de afrontar su destino. Es una nueva poética de la derrota.

Las novelas de Burnett forman un corpus temático particular dentro de esta línea. Y lo consiguen porque eligen una perspectiva que, sin obviar al detective o al policía, adoptan el punto de vista de los delincuentes. Esta focalización no es creación suya: desde que Hammet escribiera Cosecha roja, su primera novela extensa, la figura de los delincuentes empezó a ser considerada como un elemento dentro del género susceptible de mayor desarrollo literario. Hammet todavía tiene en este libro a un detective como protagonista principal, pero teje su historia a través de un sinfín de personajes que desde primera hora nos indican que una de las líneas de evolución del género pasa por dar mayor realce a los criminales. En efecto, es lo que ocurre: las denominadas crooks stories, entre las que figuran muchas obras de Burnett, ya son narraciones en las que lo narrado no se limita a las andanzas del detective, sino que son los delincuentes, sus preocupaciones, su móviles personales, su vida, los elementos que saltan al primer plano. Dicha evolución, hasta cierto punto, resulta de lo más natural: la excesiva repetición del modelo ortodoxo de Hammet y Chandler había convertido el género en una modalidad narrativa relativamente previsible. Este cambio de perspectiva renueva el enfoque de las narraciones y, de paso, incide todavía más en la profundización social, que es el rasgo esencial de la escuela norteamericana de relatos policiacos.

El cambio de tono no se limita a lo formal. También afecta al fondo de las historias. Si los gangsters eran en los primeros ensayos de literatura negra seres violentos y terribles, identificados con rasgos cuya función buscaba resaltar las cualidades del detective, en la producción de Burnett encontramos otra mirada, acaso mucho más realista: los delincuentes, pese a ser criminales, también son personas comunes, por lo general gente desesperada que, al igual que el resto de los norteamericanos, sufrían las consecuencias de la Gran Depresión. Si cometían delitos no era tanto por maldad, sino porque intentaban salir de la pobreza por una vía rápida. Su desprecio de la ley no responde pues a un 
mal atávico y terrible. Es más bien el resultado de un sistema social que no les dejaba más caminos vitales que la sumisión o la rebeldía.

La Jungla de Asfalto pertenece a este tipo de relatos: la perspectiva que predomina en la novela singulariza las circunstancias particulares de los atracadores y los equiparara a la policía, si bien (como veremos a continuación) el relato evita el maniqueísmo gratuito, que se había convertido en el gran factor de desgaste del género, al combinar la mirada de los criminales con un mensaje ideológico que, aunque con algunos matices, invoca a una cierta defensa de la ley. Esta lectura se verá después alterada en la adaptación cinematográfica de John Huston ${ }^{15}$, circunstancia a la que dedicaremos el final de este ensayo crítico.

\section{Metáforas que construyen mundos}

El estudio de la novela policial norteamericana se ha centrado especialmente en analizar las diferencias -notables, como hemos visto- que la separan de su formulación británica, cuyo origen histórico es Poe. Al vincular el crimen a su motivación social, las tramas de las narraciones del hard-boiled pierden la complejidad enigmática que tenían los relatos de la escuela inglesa. El misterio va así dando paso a la intriga -acaso por eso este género se conoce en Estados Unidos como thriller ${ }^{16}$ - y en cierto sentido cambia la significación misma de este tipo de narrativa. Lo importante ya no es cómo se comete el crimen -el nudo esencial de las obras de Agatha Christie, por ejemplo- sino el porqué se comete el delito. Los llamados crímenes perfectos -la utópica aspiración de la variante británica del género- se convierten en irrelevantes en tanto en cuanto son absolutamente imposibles: no puede haber crimen perfecto en una sociedad marcada por la imperfección, la amoralidad y el interés inmediato. Hablamos de un mundo que no es tan refinado ni elitista como el inglés y en el que no existen los mayordomos asesinos -si se me permite la caricatura- salvo como atrezzos. De ahí que un escritor tan reconocido como el argentino Roberto Piglia sostenga lo siguiente:

"Los relatos de la serie negra vienen justamente a narrar lo que excluye y censura la novela policial clásica. Ya no hay misterio alguno en la causalidad: asesinatos, robos, estafas, extorsiones, la cadena siempre es económica. El dinero que legisla la moral y sostiene la ley es la única razón de estos relatos, donde todo se paga".

15 John Huston es uno de los directores de cine más talentosos de su época. Adaptó varias novelas de detectives creando películas clásicas del género negro. Entre ellas El Halcón Maltés o Cayo Largo.

16 Jerry Palmer. op. cit. 
Se pasa pues de analizar un hecho concreto, el crimen, a diseccionar un mundo en descomposición. El crimen se convierte así en el espejo de la sociedad. Los escritores norteamericanos hablan de policías, asesinos y ladrones pero en realidad su objeto es otro: las relaciones de poder. El cristal desde el que se contempla el mundo es el delictivo, pero lo que se mira es una vida donde todo está corrompido y la ciudad, que es su ámbito esencial, se ha convertido en una verdadera jungla. Por tanto, cualquier aproximación a las novelas de Burnett debe hacerse a partir de un análisis sobre su capacidad literaria para construir metafóricamente la realidad. En este sentido, resulta muy esclarecedora la investigación semiótica del profesor Eduardo Civila de Lara, que en un trabajo de investigación sobre la adaptación de esta novela de Burnett al cine desarrolla justamente una posible definición científica de la capacidad de la novela y el cine negro para construir, a través de la asociación metafórica, distintos modelos culturales. En el caso de La Jungla, la paradoja -nos explica este profesor- es que la novela y la película, con elementos similares, construyen una metáfora divergente que en cierto sentido podría ser incluso complementaria. Algo imposible de lograr si no se cree en la capacidad polisémica de la literatura negra.

La historia de la novela de Burnett responde a un modelo canónico: se cuentan los preámbulos, ejecución y consecuencias de un atraco a una joyería en una ciudad -Midtown- del Medio Oeste de Estados Unidos. El atraco apenas ocupa un capítulo; la parte inicial y la final copan la extensión casi íntegra de la narración. Esta elección compositiva ya nos advierte de que el interés del escritor no es tanto el crimen -como venimos diciendo- sino el ambiente previo y posterior al hecho delictivo. A este factor hay que añadir otro: el título del libro. En efecto, desde antes de comenzar la lectura el autor deja claro cuál es su planteamiento: nos va a contar cómo funciona la jungla que es la ciudad. El universo en el que se desarrolla la novela negra. La elección de este título no es sólo un ejercicio de sinceridad -rasgo inherente al género-, sino una forma, como explica Civila, de facilitar una clave de interpretación inequívoca que sitúe al lector en una determinada perspectiva sobre la historia que se va a contar. Dicha elección condiciona, de partida, la mirada del propio lector. Y crea, por así decirlo, un concepto de partida que se apoya en un sistema de tópicos. El símbolo de la ciudad como jungla, que había sido esbozado ya en otras obras, adquiere en el caso de la novela de Burnett protagonismo pleno. Hasta el punto de que uno de los principales atractivos de la novela es ver cómo este marco conceptual que establece el escritor se va a ir viendo confirmado a lo largo de la propia historia. Podemos hablar de un fenómeno de enunciación bidireccional: el título remite al texto con un sesgo determinado y éste, a su vez, viene a apuntalar, con su estilo, la propuesta que supone la opción de Burnett al titular la obra. 
Este proceso metafórico, sin embargo, dista de ser perfecto. $\mathrm{O}$, al menos, podemos hablar de fisuras en su formulación. De hecho, Civila explica en su estudio que su fortaleza como recurso está ligada de forma directa a la posición concreta que adopta ante los hechos el interlocutor del libro, que en este caso es el lector. Tal y como sostenía en un inteligente artículo el profesor Georges Steiner ${ }^{17}$, un mismo texto nunca es leído de forma idéntica por dos lectores diferentes. Este espacio de incertidumbre que existe en toda lectura, que en realidad es la clave sobre la que se apoya el ejercicio de interpretación, es lo que permite a Huston subvertir los términos conceptuales de la novela de Burnett para, sin traicionarle (usa los mismos elementos del libro) llevar la historia a su terreno. Un espacio nuevo que al mismo tiempo que es objetivo persigue la subjetividad. $Y$ que es fruto de una elección personal.

El título, sin embargo, no es el único pórtico que nos propone Burnett antes de enfrentarnos a su obra. Una cita de William James ${ }^{18}$ confirma la voluntad metafórica del libro. Se trata de un texto, muy breve, en el que se reproduce la vieja idea de Hobbes $^{19}$ en Leviathan: el hombre es un lobo para el hombre. Nos enfrentamos pues a una historia donde la relación entre los protagonistas está basada en la supervivencia a toda costa y, por tanto, donde vamos a encontrar violencia, interés y todos los elementos que, siendo canónicos del género negro, configuran la singular visión del mundo de la literatura hard-boiled. En este punto convendría hacerse una pregunta: ¿Cuál es realmente la visión del mundo de La Jungla de Asfalto? No se trata de una cuestión retórica. El libro plantea una dicotomía en la que el mundo es descrito como una jungla por culpa de la maldad humana. En la novela existe un héroe -el comisario Hardy- que responde, aunque con diferencias, al modelo clásico de detective del género. Se trata de un policía con hombres a su cargo cuya función es devolver la armonía en un universo regido por la conspiración. La lucha del comisario no consiste únicamente en capturar a los delincuentes. Ésta es sólo una parte de la historia. El resto del relato nos indica que, además, tiene que hacerlo liderando a una institución -la policía- que en la novela aparece como un cuerpo corrupto. La asociación no es nueva: buena parte de las novelas negras describen a la policía como una organización donde la corrupción ambiental de los años treinta había penetrado hasta el tuétano. Burnett, sin embargo, enfoca este tema superando el tópico: es cierto que la policía está corrompida -el libro describe una escena terrible en la que dos agentes

17 George Steiner. Una lectura bien hecha. Revista Vuelta №29.

18 William James fue profesor de Psicología en la Universidad de Harvard. Hermano de Henry James.

19 Filósofo inglés que vivió entre los siglos XVI y XVII y que reflexionó sobre el absolutismo político. 
son capaces de acusar a Dix, uno de los personajes, sólo para repartirse una recompensa- pero, igualmente, es una institución cuya existencia es necesaria precisamente para que el mundo no sea un lugar sin ley. La estrategia de Burnett para superar el lugar común pasa por admitir la mayor -la corrupción del cuerpo de seguridad-y acto seguido trascenderla por el procedimiento de mostrar que, si realmente no existiera policía, la vida sería aún más salvaje. A este respecto resulta ilustrativa la primera escena del libro, que está dividido en 40 episodios, casi a modo de secuencias cinematográficas.

El arranque del libro es así el tercer elemento que refuerza el marco ideológico que elige Burnett para su libro. El primer capítulo muestra al comisario Hardy en una rueda de prensa con periodistas, que escriben sobre la corrupción en la policía, en el transcurso de la cual se abren los micrófonos de la radio policial para que éstos oigan las llamadas de socorro y el sinfín de asuntos que resuelven los agentes. Hardy admite entonces que la policía no es perfecta pero es la única barrera ante el salvajismo de un mundo lleno de fieras.

“(...) No niego que exista corrupción en el departamento de policía. Desgraciadamente la hay, y mucha, más de la que yo puedo reprimir y castigar en pocos meses. Entre los hombres que componen las fuerzas de policía hay también individuos honrados, de alta y baja graduación, que no merecen vuestras despiadadas críticas [dirigiéndose a los reporteros]. Según vosotros todo ser humano que viste un uniforme de policía es una pestilente criatura que lleva el mal olor a vuestro olfato de hombres de ideas elevadas, irreprochables, de hombre íntegramente honrados de la prensa (...) Me parece que está claro. El departamento de Policía tiene muchos problemas. No dudo que me haréis el honor de admitir que sus actividades no se limitan a la detención de rameras ni a sacar dinero del juego. Habéis estado oyendo llamadas durante veinte minutos o quizá media hora. Se oyen llamadas a todas horas, todos los días, incluso domingos y fiestas. Como veis, la policía presta un servicio público y lo presta bastante bien. (...) No continuaría en mi puesto si no fuera por esto (...) Tener la peor fuerza de policía del mundo es siempre mejor que no tener policía. La nuestra está muy lejos de ser la peor, como ustedes quieren dar a entender. Si la policía se retirara de las calles tan sólo cuarenta y ocho horas, no habría nadie que se pudiera considerar seguro ni en la calle, ni en el lugar donde trabaja, ni en su propia casa. Se verían apurados las mujeres o los niños. Volveríamos a la selva".

La cita es suficientemente explícita: el mundo es una jungla donde todo se compra y se vende. Donde todo vale. Pero las instituciones, como la policía, a pesar de estar contaminadas por este ambiente, cumplen una función social. Son necesarias. Burnett supera el maniqueísmo que había caracterizado al género para introducir claramente un mensaje moral si se quiere- que deja claro cuál es el concepto ideológico que persigue transmitir su novela. La victoria policial frente al delito puede ser puramente circunstancial. Temporal. Pero es necesaria. En todo 
caso, se trata de una victoria insuficiente. Al igual que otros héroes de la novela de policías de Estados Unidos, el comisario puede ganar una batalla incluso con un ejército imperfecto, pero la guerra no podrá ganarla. Probablemente porque está perdida de antemano.

\section{La animalización del mal y el orden imperfecto}

Una vez queda claro el paradigma ideológico a partir del cual trabaja Burnett su novela, conviene que profundicemos en los recursos que usa el escritor norteamericano para construir su metáfora sobre la ciudad contemporánea. Enumeraremos algunos sin afán de ser sistemáticos. En primer lugar debemos hablar del estilo literario. La Jungla de Asfalto, al igual que otras novelas del género, opta por una visión realista en la que, sin embargo, queda patente desde el primer momento la intención metafórica del libro. El realismo se percibe sobre todo en la separación (parcial) del arquetipo de los delincuentes. Burnett los muestra como gente que intenta escapar de la miseria y, en esta huida, no dudan en saltarse la ley. No son santos, pero tampoco demonios. La distribución del relato se hace con una cierta voluntad cinematográfica: a través de cuarenta escenas presentadas por un narrador aparentemente oculto (conductista) que, aunque hace una narración supuestamente objetiva, sin demasiadas alusiones temporales y redundancias, en realidad, aunque no entra a valorar de forma expresa los hechos, termina enjuiciándolos a través de una serie de personajes secundarios que le sirven de intermediarios para colocar su mensaje. Fundamentalmente ésta es la función narrativa de uno de los periodistas. Esta sutil forma de narrar viene así a describir y a valorar los hechos, creando además la perspectiva ideológica de la novela, sin llegar a hacerlo de forma directa. E narrador está camuflado, no inactivo.

La elección de esta técnica (un narrador oculto cuya valoración está refrendada por personajes secundarios) permite a Burnett evitar el antagonismo fácil que se había convertido en una de las causas de la degeneración de las narraciones hard-boiled. Otra forma de evitarlo es la perspectiva: la historia dedica buena parte de su desarrollo a explicar las circunstancias en las que se desarrollan los preparativos del atraco desde la mirada de los delincuentes pero, tal y como hemos mencionado anteriormente, el código moral -por decirlo así- no es el suyo, sino justo el opuesto. Este doble código, unido al tono introspectivo del libro, permite hacer más verosímil tanto la perspectiva de los criminales como la de Hardy, representante simbólico del mundo civilizado. Equilibra ambos extremos.

Sobre la visión del mundo de La Jungla de Asfalto, algunos de cuyos rasgos ya hemos mencionado, baste añadir algunas cuestiones más. 
Primero: la defensa de las instituciones es, por vía indirecta, uno de los mensajes que parece querer transmitirnos Burnett. No sólo en el caso de la policía -corrupta pero necesaria-, sino también en otros escenarios sociales, como la familia. La encarnación de la ley y el orden, luchando contra la propia corrupción que corroe al sistema (el comisario Hardy), disfruta en su intimidad de una vida familiar satisfactoria. Tiene un hogar donde su mujer cumple el rol arquetípico de la esposa: hacer la vida más agradable al héroe. Siendo tópicas, las escenas en las que Burnett nos muestra la vida marital del comisario pretenden consolidar la idea de que, para ser un héroe, hay que tener una vida ordenada.

Por contra, los delincuentes (cada uno de forma distinta) destacan por carecer de familia o abordar las relaciones sentimentales de forma caótica. Dix vive solo e ignora -casi hasta el final del libro- a la joven que está enamorada de él. Otro de los delincuentes, Louis, a quien Gus pide dinero para prestárselo a Dix, se dedica a escondidas de su esposa a actividades delictivas porque quiere mantener a su familia como si fuera un hombre honrado. Finalmente, el cerebro del golpe -el alemán Riemenschneider- siente una oscura debilidad por las jovencitas y ha tenido un sinfín de relaciones sentimentales, todas utilitarias, primarias y sin arraigo alguno. La novela nos cuenta que tiene hijos de muchas mujeres repartidos por diversas ciudades. El arquetipo del prohombre corrompido -el abogado criminalista rico que financia el golpe, y que está en el fondo arruinado- oculta sus problemas maritales iniciando ridículas aventuras compulsivas con jóvenes con las que trata de escapar de una vida basada en las falsas apariencias. Queda así claro dónde coloca Burnett la balanza del orden en mitad de tanto desequilibrio: la jungla que es el mundo sólo puede afrontarse con ciertas garantías de éxito (relativo, en todo caso) si se cuenta con una familia y se cree, a pesar de todo, en el valor de la ley. En la honestidad.

Este proceso metafórico se cierra, finalmente, con la doble dicotomía que gira alrededor del concepto de la ciudad como símbolo selvático. La urbe se presenta en la novela como un mundo hostil, oscuro, peligroso, donde los edificios son amenazantes y el hombre tiene que luchar por sobrevivir día a día. Este mundo exterior, caótico y difícil, contrasta con el mundo interior de los personajes. En parte, esta intimidad tiene los rasgos de un refugio animal, al vincular los conceptos de hogar y la familia. Tanto el comisario Hardy como algunos de los delincuentes que participan en el atraco se reservan para sí un espacio de protección temporal, necesario para sobrellevar la existencia en una jungla de asfalto.

La metáfora general, que antes ya hemos explicado que se formula desde el arranque mismo del libro mediante el título, la cita de apertura y la primera escena (la rueda de prensa), se ve intensificada a medida que discurre la historia tanto por los propios hechos como por el registro 
descriptivo al que recurre Burnett. La retórica resalta la animalización de todos los seres y los espacios donde se desarrolla la acción narrativa. Sobre el marco conceptual de la ciudad-jungla se contraponen dos elementos: el orden imperfecto, que es la policía y, por extensión la civilización; y el ecosistema de los animales (los delincuentes) que viven cobijados en madrigueras y parecen alimañas, seres prácticamente inhumanos a pesar de ser hombres corrientes cuyo destino, salvo excepciones muy concretas, les ha obligado a ser así. No es éste el contexto pertinente para profundizar mucho más en este mecanismo de degradación óptica y simbólica de los personajes. Baste decir que se trata de una constante a lo largo de todo el libro que pretende conseguir la coherencia expresiva necesaria para que la metáfora conceptual de la jungla de asfalto no quede limitada a un nivel puramente superficial, sino que sea la esencia misma de la novela. Su naturaleza propia.

\section{La adaptación cinematográfica: la subversión del modelo}

La adaptación al cine de muchas de las novelas del género policiaco norteamericano es una constante. Las mejores obras de Hammet -El Halcón Maltés, por ejemplo- o de Chandler -El largo adiós- son más conocidas por sus variantes fílmicas que por sus textos originales. Este fenómeno es inherente a la cultura popular, el contexto donde nacen las narraciones negras estadounidenses. En cierto sentido consolida también la idea de que su importancia literaria radica en su capacidad para convertir los arquetipos -psicológicos, ambientales- en universales. Igual que sucede en el western. No es extraño pues que apenas un año después de su publicación -la novela es de 1949- John Huston, uno de los directores más originales del Hollywood de la época, guionista en sus inicios en la industria, decidiera dirigir una película basada en la obra de Burnett. Huston era reincidente: muchas de sus obras parten de adaptaciones literarias. $Y$ un perfecto heterodoxo: sus versiones cinematográficas no responden siempre a un calco de los libros, sino que son consecuencia de su lectura subjetiva de las obras. Sobre esta cuestión incide, con enorme lucidez, el profesor Civila de Lara, que en su investigación semiótica sobre los modelos culturales presentes en la narración de Burnett y en la película de Huston explica cómo el director de cine comete un proceso de subversión completa del marco ideológico establecido de origen por la novela. Este tránsito, sin embargo, es extraordinariamente original, puesto que se apoya en los mismos elementos que el propio Burnett había introducido en su libro, si bien con una perspectiva e intensidad diferente al que presentará la película.

Huston hace una adaptación lícita pero, digamos, con una clara vocación heterodoxa. Se trata de una transmutación. Encuentra en el seno 
de la propia novela los recursos necesarios para alterar la lectura intencional de Burnett: el paradigma ideológico sobre el que se sustenta la metáfora de la ciudad-jungla. El método elegido permite a Huston llevar la historia a su universo sin llegar a traicionarla, pues su visión de la jungla, siendo distinta a la del libro, se arma con recursos del propio escritor. No me extenderé en demasía sobre las técnicas mediante las cuales se produce este proceso, dado que este ensayo académico no está dedicado a las fórmulas de adaptación entre el lenguaje cinematográfico y el literario. Tampoco es un tratado de semiótica que deba profundizar en las maneras de construir símbolos culturales divergentes a partir de elementos comunes. Enumeraré, sin embargo, algunos ejemplos de cómo se produce esta inversión ideológica que convierte la novela de Burnett en una obra distinta en cine, siendo en realidad fiel a su origen.

La adaptación de Huston potencia unos elementos y prescinde de otros. Lo que quiere contar el director de cine es una visión alternativa de la jungla de asfalto en la cual cambiarán los roles de las instituciones -la policía- y de los delincuentes. Es una cuestión de coherencia personal o, por así decirlo, de justicia poética. Huston siente una evidente fascinación por el mundo de los perdedores, los outlaw, personajes clásicos en la literatura y el cine de Estados Unidos, a los que ha dedicado otras películas como Fat City ${ }^{20}$. Es justo a este terreno donde el director norteamericano traslada la novela de Burnett por un procedimiento que consiste en desnudar al relato de ciertos rasgos que fortalecen la dicotomía conceptual con la que opera el libro. En primer lugar, Huston elimina del filme dos de los personajes que en la novela tienen la función de consolidar el discurso del comisario Hardy y mostrarlo como un hombre honesto y sin tacha: la mujer y el periodista. Sin el reportero lo que hace Huston es eliminar la voz del personaje que avala la visión del héroe policial. Sin la esposa el comisario pierde también el concepto de estabilidad que en la novela se introducía para forzar una oposición expresiva entre el mundo ordenado de la ley y el orbe selvático de la ciudad. La película suprime otras escenas y cambia de sitio el episodio clave de arranque del libro: la rueda de prensa en la que el comisario Hardy hace la vindicación pública de la necesidad de contar con un cuerpo de policía. Huston la coloca ahora al final del filme con la intención de que ratifique su propia visión de la historia. No es un atrio, sino un colofón.

¿Cuál es esta lectura de la novela de Burnett? Esencialmente la opuesta a la que representa la figura del héroe del libro. Huston no si-

20 John Huston rodó en 1972 esta película sobre boxeadores fracasados, un tema que le era especialmente grato, basándose en la novela escrita por Leonard Gardner en 1969. 
lencia el papel del comisario -otra cosa distinta hubiera sido traicionar el relato original- pero lo sitúa en un plano equiparable al de los delincuentes. El contraste metafórico del libro se invierte así hasta neutralizarse. ¿Qué es lo que entonces emerge? Fundamentalmente el punto de vista de los delincuentes, que es el que Burnett escogió como tema pero relativizó al configurar el marco ideológico del libro. En igualdad de condiciones, desde el mismo plano jerárquico, la novela muta: la jungla permanece presente pero la función de los dos mundos se intercambia. Los criminales ya no son vistos como alimañas malignas, ni siquiera en el plano retórico, sino como delincuentes que persiguen la liberación frente a una sociedad incapaz de integrarlos. Huston está buscando, es indudable, una épica que es la de los perdedores y que en cierto sentido estaba escondida dentro de la novela. La caracterización de la policía como un cuerpo corrupto se intensifica -al situarse al final del filme la vindicación de Hardy ya no condicionan el juicio inicial del lector, sino que forma parte de la visión parcial del personaje- y el retrato hostil de la ciudad no se debería ya a los criminales, sino a un mundo en el que el entramado, el sistema, es la verdadera selva. Los criminales quedan así categorizados como antihéroes individualistas incapaces de sacrificar su libertad y sus sueños para asumir los principios de una sociedad que, precisamente por ser así, los rechaza. Las instituciones ya no son la solución, sino el problema mismo. Los criminales pasan a ser las víctimas de una ley (Hardy) que no es tan épica, ni tan necesaria, sino que aplica un mismo patrón a todas las personas. En este sentido, Civila de Lara habla de que en la novela predomina "un modelo sintagmático de cultura que hunde sus raíces en el ideario del racionalismo ilustrado, y que da primacía a la organización social y a las estructuras racionales por encima de los dictados de la naturaleza, los sentimientos o los instintos". $Y$ añade:

"El hombre se define en este modelo por su función social, por lo que la sumisión a la norma se entiende como la regla fundamental. Dentro de una creencia absoluta en la idea de progreso, la aspiración fundamental del hombre debería ser la adquisición de mayor autoridad: ocupar un puesto jerárquicamente más elevado en la estructura, aunque sea sólo para poder servir mejor a la sociedad, y colaborar de modo más comprometido en el avance de un proyecto común"21.

Por contra, el modelo cultural del filme es "asintagmático". Esto es: se inscribe en la visión del mundo que nos ha legado el romanticismo, si bien bajo una formulación conceptual adaptada a los tiempos modernos. En palabras del profesor Civila:

21 Eduardo Civila de Lara, op cit. pág 273. 
"Según este modelo [asintagmático] la organización social es, por definición, nociva y alienante para el hombre, ya que lo limita y lo aleja de su verdadera esencial natural; aquello que lo pone en relación con el orden cósmico del cual ha sido expulsado, y del que aún podemos encontrar o vislumbrar en el mundo de los sueños, el inconsciente, las experiencias estéticas y amorosas $y$, en general, en el mundo de los sentimientos y las intuiciones. La idea de progreso se considera una perversión, ya que lo único que importa es el origen: la naturaleza. De este modo, en lugar de la autoridad, la meta del hombre en este caso va a ser el situarse, en lo posible, al margen del entramado social. Esto es, la libertad".

No se trata de una lectura subjetiva ni gratuita. El final que Huston elige para su propia película es sintomático: uno de los atracadores, Dix, al que los demás apodan el guapo en la novela, un matón maltratado por la vida que idealiza sus orígenes irlandeses y sueña con un onírico retorno al hogar que es la granja familiar -el mito de la tierra está en las raíces culturales de Estados Unidos-, muere en la antigua propiedad de su familia en una especie de regreso a los años de su infancia. Se trata de un retorno al hogar imposible: su familia tuvo que vender la propiedad, con los caballos incluidos, por los problemas económicos derivados de la Gran Depresión. La huida hacia el pasado idealizado de Dix, que es uno de los motores de su personalidad, queda así frustrada porque ninguno de nosotros podemos volver al sitio del que vinimos, aunque estemos toda la vida intentándolo. El regreso al pretérito ancestral, que es la metáfora de la felicidad pasada, corrompida por una realidad negra y cruel, es una utopía inviable. Pero, no obstante, llena de dignidad a un personaje que desde una óptica convencional no sería más que un criminal. La subversión del marco ideológico de la novela queda pues consumada y sustituida por la nueva visión de Huston. El círculo se cierra.

\section{Conclusiones}

Las dos escuelas clásicas de la novela policiaca -la británica y la norteamericana-, fuentes de las que beberían el resto de variantes geográficas y estilísticas de este género literario contemporáneo, centran su objeto en el mismo asunto -el crimen, el delito- pero con perspectivas dispares. Mientras la primera, evolución refinada de la línea iniciada por Edgar Allan Poe en sus relatos, sitúa sus ingredientes favoritos en el misterio y la razón, la segunda no entiende otro criterio de verdad que la experiencia, recurriendo pues a la intriga como el método narrativo esencial. El arquetipo del detective difiere entre ambas: del investigador informal o aficionado que deduce los hechos se pasa a un héroe, gene- 